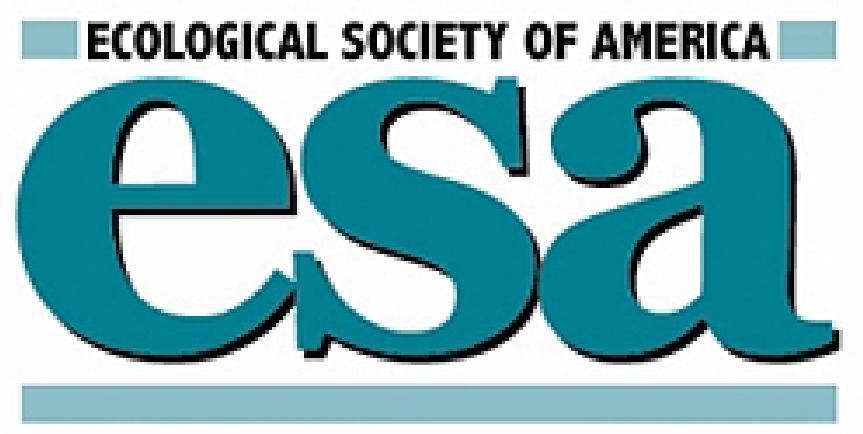

Developing a Field of Landscape Ecotoxicology

Author(s): John Cairns, Jr. and B. R. Niederlehner

Source: Ecological Applications, Vol. 6, No. 3 (Aug., 1996), pp. 790-796

Published by: Ecological Society of America

Stable URL: http://www.jstor.org/stable/2269484

Accessed: 12/03/2014 10:31

Your use of the JSTOR archive indicates your acceptance of the Terms \& Conditions of Use, available at http://www.jstor.org/page/info/about/policies/terms.jsp

JSTOR is a not-for-profit service that helps scholars, researchers, and students discover, use, and build upon a wide range of content in a trusted digital archive. We use information technology and tools to increase productivity and facilitate new forms of scholarship. For more information about JSTOR, please contact support@ jstor.org. 


\title{
DEVELOPING A FIELD OF LANDSCAPE ECOTOXICOLOGY
}

\author{
JOHN CAIRNS, JR. \\ University Center for Environmental and Hazardous Materials Studies and Department of Biology, \\ Virginia Polytechnic Institute and State University, Blacksburg, Virginia 24061 USA \\ B. R. NIEDERLEHNER \\ University Center for Environmental and Hazardous Materials Studies, Virginia Polytechnic Institute and State University, \\ Blacksburg, Virginia 24061 USA
}

\begin{abstract}
Since toxicants are spread over ecological landscapes, it seems likely that they have effects at that level of ecological organization. Landscape ecotoxicology examines the effects of toxic chemicals on larger scales than traditional environmental toxicology. This approach is characterized by the use of endpoints appropriate to the spatial scale across which a toxicant is dispersed, attention to interactions between physical and temporal patterns and the process of ecological impairment, and integration of multiple lines of evidence for toxicity at various scales. In addition, landscape ecotoxicology seeks predictive models in order to influence human actions before environmental damage occurs. Integrating information from damaged systems, toxicity tests, simulation models, and biomonitoring of healthy systems provides the best basis for decisions. Rapid progress in landscape ecotoxicology is expected as scientists incorporate tools, such as remote sensing and spatially explicit simulation models, and then calibrate these models using data from long.term biomonitoring of large areas. Further integration into combined socio-economic-ecological models is also possible.
\end{abstract}

Key words: cumulative impact; ecotoxicology; endpoints; landscape pattern; scale effects; stressed ecosystems; toxic stress.

\section{INTRODUCTION}

The term "landscape ecology" has been credited to Carl Troll, a geographer who used it to describe the intersection between geography and ecology (Troll 1939). The term is now commonly used to describe ecological studies on a scale large enough to include heterogeneity in ecosystems, usually larger than square kilometres (Golley 1995). Landscape ecology has provided new understanding about the spatial arrangement of ecosystems; the flow of energy, materials, and organisms between ecosystems; and the changes in structure and function of landscapes resulting from both anthropogenic and natural events (e.g., Forman and Godron 1986). However, when problems arise from the discharge of toxic chemicals on large scales, the tools and perspectives of toxicology must be added to the transdisciplinary mixture. Landscape ecotoxicology examines chemicals dispersed over a large spatial scale and their potential for adverse effects on biological systems, including humans.

Increasing the scale of a toxicological study may require many simultaneous changes in approach. O'Neill et al. (1986) suggest that responses to chemical stress occur at multiple scales. And while changes on larger scales arise from interactions on finer scales, it is difficult to predict the form, magnitude, and significance of changes resulting from chemical contamination across scales. Landscape ecotoxicology explic-

${ }^{1}$ Manuscript received 15 September 1994; revised 18 May 1995; accepted 28 August 1995. itly considers the difficulties of extrapolating across scales in developing methods for evaluating effects of large-scale chemical contamination. As a consequence, landscape ecotoxicology is characterized by endpoints appropriate to the spatial and temporal scales across which a toxicant is dispersed, attention to interactions between the patterns and the processes of ecological impairment, and integration of multiple lines of evidence for toxicity at various scales.

In addition, landscape ecotoxicology seeks to improve management decisions by providing wellfounded and timely information on the risk posed by chemicals. As such, landscape ecotoxicology requires an emphasis on prediction because, in order to prevent damage, it is necessary to influence human actions before environmental damage occurs. Methods for estimating the probability of an adverse effect of a given magnitude resulting from a human activity are referred to as environmental risk assessment and are an area of rapid development, including the development of methods appropriate to large-scale problems (Hunsaker et al. 1990, Suter 1990, Graham et al. 1991).

In this paper, we describe some of the types of research being carried out in landscape ecotoxicology. It is by no means a comprehensive review but, instead, a brief look at the variety of approaches. And, while much of the work on landscape patterns and disturbance deals with landcover changes and natural disturbances, we focus on those studies evaluating the adverse effects of chemical contamination. 


\section{What MaKes LANDSCAPE Ecotoxicology DIFFERENT?}

\section{Endpoints}

Chemical stresses vary in spatial extent, recurrence interval, and intensity (Table 1). Small, one-time spills of a degradable chemical may have a restricted spatial and temporal impact; the practice of seasonal pesticide or fertilizer applications may have regional and longterm effects; and the accident at Chernobyl caused contamination on a continental scale. As the spatial scale of chemical exposure changes, other characteristics of the pollution stress tend to change: the source of the chemical changes from one identifiable locus to many diffuse sources; the stress changes from a single agent to co-occurring combinations of agents; the intensity of the stress changes from acute to chronic; and indirect effects may be increasingly important. Cumulative impact, where individually minor changes become significant as they aggregate through time or space, is also important at the landscape scale.

However, while toxic substances are distributed over many scales and, presumably, have effects at many scales, studies designed to link chemical contamination and biological impact have generally been conducted at more uniform spatial and temporal scales that are convenient and practical for investigators and regulatory agencies. With the important exception of manipulative field experiments (e.g., Woodwell 1962, Barrett 1968, Geckler et al. 1976, Schindler 1988, Wright 1991), most of what is known about causative links between chemicals and biological impairments has been derived from the study of the growth and reproduction of one species at a time. Most field assessments focus on a limited number of commercially important populations.

It is not practical to monitor every potential response to chemical impact at every hierarchical level. In order to narrow the field, criteria have been developed for selecting useful endpoints for studies that hope to influence management decisions. Suter (1990) points out that endpoints directly related to a society's environmental goals as expressed in legislation would be most useful, but these goals are often amorphous and unmeasurable. Instead, a logical progression from societal goals to a selection of environmental values worthy of protection, and then to measurable responses, must take place (Suter

TABLE 1. Examples of disturbances at various scales.

\begin{tabular}{ll}
\hline \hline 1. Local & $\begin{array}{l}\text { Heavy metal pollution } \\
\text { Oil spills } \\
\text { Air pollution } \\
\text { Pesticides } \\
\text { Fertilizers/nutrients }\end{array}$ \\
3. Regional & $\begin{array}{l}\text { Air pollution } \\
\text { Salinization } \\
\text { Air pollution- "acid rain," } \mathrm{Hg} \\
\text { 4. Continental }\end{array}$ \\
5. Global & $\begin{array}{l}\text { Increases in atmospheric } \mathrm{CO}_{2} \\
\text { Inces } \mathrm{UV}-\mathrm{B}\end{array}$ \\
\hline
\end{tabular}

TABLE 2. Some response endpoints at the landscape scale (from Suter 1990, Hunsaker et al. 1990, Hunsaker and Carpenter 1990, Holl and Cairns 1995).

\begin{tabular}{|c|c|}
\hline I. & $\begin{array}{l}\text { Population range for indicator species: sensitive, } \\
\text { tolerant, exotic, or economically important }\end{array}$ \\
\hline II. & Patch species richness or diversity \\
\hline III. & Patch productivity \\
\hline IV. & $\begin{array}{l}\text { Rate of export of nutrients, soil, energy, animals, } \\
\text { or pollution }\end{array}$ \\
\hline V. & $\begin{array}{l}\text { Resistance to additional disturbance, i.e., suscep- } \\
\text { tibility to pests, fires, floods, droughts, etc. }\end{array}$ \\
\hline VI. & $\begin{array}{l}\text { Resilience to additional disturbance, i.e., rate of } \\
\text { recovery from pests, fires, floods, droughts, etc. }\end{array}$ \\
\hline VII. & Landscape aesthetics \\
\hline VIII. & Climatic change \\
\hline \multirow[t]{8}{*}{ IX. } & Indices of landscape pattern \\
\hline & $\begin{array}{l}\text { A. Habitat proportions (relative proportions of land } \\
\text { use or vegetation cover types on the landscape) }\end{array}$ \\
\hline & $\begin{array}{l}\text { B. Dominance (degree to which the landscape is } \\
\text { dominated by a particular land type) }\end{array}$ \\
\hline & C. Patch size and perimeter-to-area ratio \\
\hline & $\begin{array}{l}\text { D. Contagion (degree to which the landscape is dis- } \\
\text { sected into land type patches that are small and } \\
\text { separated vs. large and contiguous) }\end{array}$ \\
\hline & $\begin{array}{l}\text { E. Fractal dimension (the complexity of shapes in } \\
\text { the landscape) }\end{array}$ \\
\hline & $\begin{array}{l}\text { F. Connectivity (degree to which individuals of a } \\
\text { given species can travel about) }\end{array}$ \\
\hline & $\begin{array}{l}\text { G. Patton's Diversity Index (amount of edge per } \\
\text { unit area) }\end{array}$ \\
\hline
\end{tabular}

1990). The best endpoints are both biologically and socially relevant, easily measured, sensitive, applicable to many kinds of stress, and appropriately scaled (e.g., Cairns et al. 1994). What large-scale endpoints will best fulfill these needs? Table 2 provides examples of endpoints that have been suggested for landscape-scale studies.

Some of these endpoints are identical to those used at smaller scales. For example, use of indicator species is ecosystem specific, but is a well-developed approach useful on many spatial scales (e.g:, Ryder and Edwards 1985). Other endpoints do not exist at lower hierarchical levels. Investigators have much less experience with these endpoints, and experience is needed to identify those endpoints that will be consistently useful over diverse landscapes, chemical stresses, and stress intensities. Descriptions of severely damaged landscapes have provided a starting point for identifying endpoints that respond to pollution stress. For example, exposure to radiation created a very clear gradient of habitat type with distance from the source and increased susceptibility to insect damage (Woodwell 1962). Severe air and soil pollution from a smelter resulted in a more open canopy, severe soil loss, decreased patch diversity (depauperate tree, moss, lichen, litter invertebrate, and wildlife communities), increased presence of exotic species, decreased resistance to drought, and decreased resilience following fire, i.e., the polluted forest recovered more slowly from the natural disturbance of fire (Jordan 1975, Beyer and Storm 1995). Mixed conifer forests subjected to chronically high ozone levels had a more open canopy (Miller 1973). Nutrient loss 
was a feature of landscapes damaged by smelter emissions (Jackson and Watson 1977). Suter (1993) suggests that severe chemical stress may be necessary to affect directly the indices of landscape patterns in Table 2. However, indirect effects on these same landscape indices are possible at more moderate chemical exposures. For example, in a simulation, Graham et al. (1991) found that changes in forest edge were a probable result of the interaction between low ozone exposure and bark beetle attack.

\section{Modifying factors}

Landscape pattern may be most useful in explaining differences in the effects of more moderate chemical stresses on other endpoints. Hunsaker and Carpenter (1990) make an important distinction between a response indicator (i.e., a characteristic of the environment measured to provide evidence of the biological condition of a resource), a habitat indicator (i.e., a physical attribute characterizing conditions supporting life in absence of pollutants), and an exposure indicator (i.e., a characteristic measured as evidence of a response indicator's contact with a stress). They suggest that many of the landscape indicators that can be remotely sensed are primarily useful as habitat or exposure indicators.

Landscape features clearly modify the fate of chemicals and the pattern of exposure to pollution. For example, forests at higher elevations are exposed to more cloud deposition, and the edges of forests are exposed to deposition not only from above but horizontally (see review by Lovett 1994). The importance of these landscape features in modifying exposure and subsequent ecological outcome was clearly demonstrated in the severely polluted forest communities around Sudbury, Ontario, where hilltops were denuded while valley bottoms and protected slopes retained vegetation (Freedman and Hutchinson 1980).

Landscape features and land uses also modify the ability of the landscape to restrict chemical damage spatially. The spread of fertilizer and pesticides from farmlands is facilitated by corridors provided by roads (Bennett 1990) and is restricted by both forest (Peterjohn and Correll 1984) and wetland habitat patches (Johnston et al. 1988). In other cases, the type of pollution is transmuted by landscape features; acid inputs to wetlands resulted in metal exports to adjacent ecosystems (Gorham et al. 1984).

Landscape factors also differentiate the inherent susceptibility of sites to damage from toxic materials. For example, local geology and buffering capacity substantially affect the latency and magnitude of responses to acidic precipitation (Bird and Rapport 1986), and local geology affects the potential for groundwater contamination from fertilizer use (Halliday and Wolfe 1991).

Landscape pattern may also modify the speed of recovery (i.e., resilience) from localized damage by pro- viding routes for recolonization by important species (Hunsaker and Carpenter 1990, Barrett and Bohlen 1991, Fahrig and Freemark 1995). If there are no appropriate corridors, recovery is delayed. If the extinction is widespread (affecting the metapopulation) rather than local, no individuals may be left to disperse into the affected area; recovery will be slow and adverse effects will readily propagate.

Landcover change is not only a major cause of biological impairments through habitat modification or loss but also a significant source of chemical exposure (Vitousek 1994). On a landscape scale, the cumulative loss of wetlands has had a demonstrable effect on stream water quality in the Minneapolis-St. Paul area (Johnston et al. 1988). Similarly, White et al. (1981) estimate that each hectare of the $274 \times 10^{3}$ ha of farmland brought into production in Georgia between 1973 and 1976 has increased nitrogen runoff to streams by $8.35 \mathrm{~kg}$ annually.

\section{PREDICTION}

A primary goal of the science of landscape ecotoxicology must be to develop techniques to predict accurately the environmental outcome of the release of a toxic chemical on a landscape scale before such a release actually occurs. Only a few ways exist for making such predictions on any scale:

a) Generalize from similar systems that have been damaged by toxic materials.

b) Experimentally stress a physical model of the system of interest and observe the outcome.

c) Study the system of interest thoroughly enough to describe the interactions between components, construct a simulation model of these interactions, and then predict the effects of a disturbance on the system by manipulating the components of the model in the same way the toxicant affects them.

d) Study the system of interest thoroughly enough to recognize early departures from desirable conditions over time, i.e., biomonitor natural systems and define ecosystem health.

However, there are problems in extending each of these approaches to landscapes, regions, continents, and globes.

\section{Damaged natural systems}

Studies of damaged systems provide convincing evidence of the costs of uncontrolled environmental damage. These studies often spring from obvious and unacceptable environmental damage and move from the top down; some environmental outcomes and their significance are known, but the cause may be unknown. With damage already in place, causes are identified, sources are remediated, and recovery starts. In the process, much is learned about chemical fate, modifiers of response, and recovery.

Prevention of damage is possible only if environmental outcome is anticipated before the fact. Because 
every landscape presents a unique history of events, arrangement of elements, combinations of chemical exposures, etc., experience with one system is rarely directly applicable to a prediction of outcome in another. Information must be extrapolated from gross to subtle damage, from one spatial pattern to another, and from one mix of causative agents to another. The obstacles are daunting.

However, some information relevant to predictions at the landscape level is found in damaged natural systems. Unacceptable damage in natural systems provides an obvious starting point for selecting appropriate endpoints. In addition, methods similar to those for epidemiological studies of human health effects can be used with damaged natural systems. Gradient studies evaluate community changes across increasing intensities of chemical exposure (e.g., Westman 1979). Synoptic surveys examine the relationships between chemical, physical, and biological data across many ecosystems. Consistent relationships between a biological impairment and chemical exposure in the absence of concurrent gradients in other parameters provide strong support for a cause-and-effect relationship. For example, Vollenweider (1975) developed predictive models from synoptic surveys of lakes that relate nutrient loading to eutrophication. Most synoptic studies focus on one ecosystem type at a time, so, while they are often regional, pattern is not a focus.

\section{Toxicity tests}

Toxicity tests work from the bottom up: the cause (a specific chemical) is known and response is determined in systems of increasing complexity. Toxicity tests are the controlled exposure of biological units to toxic substances and the observation of outcome. Designed tests allow the researcher to demonstrate a causative link between a chemical and a biological impairment that is impossible to show in the complex and unreplicable natural world. However, it is difficult, expensive, and often unethical to sacrifice larger landscape units to testing schemes. For these reasons, largescale testing is limited by practicality. Instead, toxicity tests must make use of experimental models, smaller biological units selected as representations of something existing in nature. For example, if society wishes to preserve the sustainability of forest ecosystems, then the experimental model chosen for testing might range from growth of individual tree seedlings to productivity of forest plots. For the most efficient generation of information, an experimental model is ideally as simple as it can be while still containing all the structures and functions that are relevant to the outcome. If an experimental model is chosen that is too simple and leaves out structures and functions that materially affect the outcome, the accuracy of predictions is jeopardized. Choosing an experimental model that is overly complex increases testing costs without significantly increasing the amount of information obtained. Prac- tical constraints dictate that toxicity testing in landscape ecotoxicology be largely modular. Tests of specific interactions can be conducted and then integrated into a simulation model to extrapolate to larger spatial scales (Aber et al. 1993).

\section{Simulation models}

Simulation models are explicit statements of systems of relationships. Barnthouse (1992) suggests three basic reasons for developing simulation models: to explain, to predict, or to extrapolate. To explain a behavior, enough basic information must be available to break the behavior into constituent parts and their interactions, and then put them back together again. The model then can be used to diagnose or explain observed behavior in terms of underlying, constituent causes. Prediction involves making projections that can be experimentally verified. Extrapolation involves making projections that are impractical to verify.

Simulation models in ecotoxicology vary from the very basic (e.g., acute-chronic ratios, or safety factors) to the very complex (e.g., the effects of climate and chemical changes on biogeochemical cycles in regional forests [Aber et al. 1993]). Most simulation models in landscape ecology are explanatory. The objective of such models is to explain a behavior at one hierarchical level in terms of interactions at a lower level. These models are useful for connecting disparate areas of research, generating hypotheses, and pointing out gaps in knowledge. In contrast, most simulation models in regulatory usage are predictive. The probability of an adverse ecological effect resulting from some human action is estimated. Even very crude models can be useful for decision making because the models often replace unspoken assumptions about the relationships between components. Explicit simulation models make the reasoning underlying many decisions more accessible and subject to review.

While there are numerous ecosystem-specific models (e.g., Taylor et al. 1994), there are fewer regional-scale biological models that evaluate risk of human actions (Hunsaker et al. 1990). Gherini et al. (1985) developed an integrated lake-watershed acidification study (ILWAS) model. Graham et al. (1991) demonstrated a spatially explicit model of the interactive effects of ozone and bark beetles on forest pattern and water quality. Aber et al. (1993) suggest strategies for linking spatial data bases with individual data-intensive models for component ecosystems, in order to make regional predictions.

There is considerable controversy about when a model has earned sufficient credibility for management use (Barnthouse 1992). Certainly, models used to support expensive changes in pollution management will be challenged. Harwell and Harwell (1989) point out common problems with simulation models: a reliable data base on which to construct the model is rare, variables are aggregated, and relationships are often oversim- 
plified to linear solutions. Uncertainty of model predictions (O'Neill et al. 1982) is recognized as an essential factor in evaluating the relative merit of models in a formal environmental risk assessment. However, uncertainty will tend to increase with scale. Obviously, a simulation model that has been successful at predicting (or hindcasting) outcome in a variety of systems deserves greater consideration than one that has not. If this standard cannot be attained, which will be true for many large-scale models, then the best comparisons of credibility come from the predictive success of the component parts of the model (Aber et al. 1993) and calculations of uncertainty propagation. While publication in peer-reviewed forums will improve models by checking inclusiveness and form against conventional wisdom, this will only confer consistency, not predictive credibility. Perfectly consistent models may still have errors of omission and chaotic components that make prediction of outcomes impossible. Agreement between predictions from independently derived models is another encouraging sign of consistency. Consistency may be enough when the purpose is to rank risks in order to guide choices between alternatives, especially when comparing alternatives at the same scale. Even with considerable uncertainty, models are useful in regulation because they make the assumptions about interactions explicit and subject to review. Models clarify what is known and what needs to be known.

\section{Biomonitoring of natural systems}

A fourth source of information is useful for evaluating environmental outcome of toxic disturbance at a landscape scale. The most direct evidence of environmental condition is provided by direct examination of the landscape itself. While gross damage is easy to detect, the understanding of natural systems over large scales and long time periods is minimal. Normal operating ranges for natural processes are not known, and this makes it impossible to judge the importance of observed changes by distinguishing the early stages of damage from background variability. Biomonitoring natural systems over long time periods will provide information on consistency, change, and direction in natural systems. Without this information, interpreting information from other sources is impossible.

It is increasingly our conviction that much of the toxicological information at the landscape level must at first be based on monitoring trends in condition of natural systems. One of the reasons for arriving at this tentative conclusion is the increased research emphasis on ecosystem condition. Many monitoring programs exist; a few examples are the U.S. Department of Agriculture and the U.S. Environmental Protection Agency's (USEPA) Forest Health Monitoring program, the USEPA's EMAP program, the National Science Foundation's LTER program, and the National Research Council's U.S. Global Change Research Program. The obvious drawback to biomonitoring natural systems as a means of environmental protection is that damage must occur before it can be detected. Biomonitoring is a reactive management system rather than a predictive one.

When sufficient case histories are available to begin defining normal operating ranges for landscape structures and functions, predictions on ecosystem health can be made in the same way that predictions are now made for human health (e.g., Costanza et al. 1992). After all, landscapes are not the only biological unit for which toxicity tests are impractical and unethical. The effects of toxicants on human health also must be discerned largely without controlled tests. However, this has not proven an insurmountable barrier. While the tobacco industry still disputes a causative relationship, prudent people avoid smoking. Consequently, a landscape epidemiology may prove similarly useful in making decisions about future actions.

\section{Integrated assessments}

Obviously, the strongest evidence of effects of toxic substances on landscapes integrates all four kinds of information: studies of damaged natural systems, toxicity tests, simulation models, and biomonitoring. Experiences with damaged natural systems provide convincing evidence of the great cost of uncontrolled environmental damage. Both field studies with damaged systems and toxicity tests can identify endpoints for assessments that are efficient (so they can be made frequently) and occur early in the progression of impact so that corrective measures can be taken quickly. Toxicity tests alone can establish a causal link between a chemical agent and a biological impairment. Biomonitoring will provide simulation models with the long-term data needed to construct and calibrate better models. In addition, simulation models will permit predictions of environmental outcome before damage occurs, extrapolations to untestable spatial scales and time spans, and aggregation and interaction of cumulative impacts.

Research integrating several of these approaches to assessing chemical exposures on landscape scales provides the best examples of landscape ecotoxicology. For example, the suite of evidence linking ozone exposure and damage in both sage and forest communities has combined studies on damaged ecosystems, laboratory toxicity tests, models, and biomonitoring (e.g., Miller 1973, Westman 1979, Woodman and Cowling 1987, Westman and Price 1988, Westman and Temple 1989). More recent studies have focused on chemical effects on flows between ecosystem components, indirect effects, and emergent endpoints. For example, Graham et al. (1991) integrated GIS data on the Adirondack forest with land-cover and water-quality models and a model for the interaction between ozone exposure and bark beetle damage to conifers. Other spatially explicit models have been developed by integrating models of agricultural nonpoint-source pollution with the GIS, which 
locates relevant physical features of watersheds for investigating the ecological consequences of various farming practices (e.g., Brusven and Walker 1995). Clifford et al. (1995) integrated maps of dieldrin contamination in soils at a Superfund site, tissue concentrations, and food-web information to estimate exposure across the foraging range for various organisms. These spatially and temporally weighted exposures were compared to benchmark concentrations to derive spatially explicit estimates of risk. Minns et al. (1990) integrated models for sulfate deposition, buffering capacity, and loss of biotic diversity in lakes with acidification to produce regional assessments of species loss in an entire class of ecosystems under different emission scenarios.

In addition to integrating the lines of ecotoxicological evidence, the best information on risk can be integrated with other types of information used in making decisions: economics, sociology, land-use planning, political science, etc. Various GISs with spatially referenced information on administrative boundaries, landcover, geology, socioeconomic status of human residents, etc., can be overlaid on each other to integrate and model these types of information interactively (Van Voris et al. 1993). Other integrated socioeconomic-ecological models in which human behaviors interact with pollution effects are described by Grossmann (1994). Given the potential for chaotic behaviors in both the global ecological systems and in the human sphere, Grossmann suggests that features for accommodating the unexpected need to be a part of all models used for prediction. Further integration of human behaviors into ecological models depends in part upon development of common units for human and natural resources that are less biased than monetary units (e.g., Turner et al. 1988). Better environmental accounting systems will facilitate socio-economic-ecological modeling and will make possible more valid comparisons of the relative uncertainties from economic and ecological components on landscape scales.

\section{CONCLUSIONS}

Increased attention to scale in evaluating the risks posed by chemical use and disposal will improve environmental protection. While ecotoxicological endpoints at population levels are more developed, continued observation at the landscape scale may provide unique information about emergent and cumulative responses to pollution. Our ability to evaluate effects on larger scales is likely to improve rapidly because of simultaneous developments in disparate disciplines. Continued collection of data across large spatial and temporal scales in various monitoring programs provides essential information about landscape structure and function. The continuing development of technical tools, such as GIS-interfaced models and remote sensing, make it increasingly possible to monitor large systems and make predictive models spatially explicit. The best approach will still integrate data from damaged systems, toxicity tests, simulation models, and biomonitoring. Because the predictive models used in environmental risk assessment will shape the future environment, it is important to review these methods to assure that they do embody the best of current scientific understanding. Even more than at smaller spatial scales, management decisions on this larger scale will have to be made with uncertainties. However, these uncertainties may be characteristic of the scale and common to all the information and options being weighed by decisionmakers, both ecological and socioeconomic.

\section{ACKNOWLEDGMENTS}

We are indebted to Teresa Moody for transcribing the dictation for the first draft of the manuscript and to Darla Donald for seeing that instructions to authors were met. We are also most grateful for the constructive suggestions of anonymous reviewers.

\section{LiterATURE Cited}

Aber, J. D., C. Driscoll, C. A. Federer, R. Lathrop, G. Lovett, J. M. Melillo, P. Steudler, and J. Vogelmann. 1993. A strategy for the regional analysis of the effects of physical and chemical climate change on biogeochemical cycles in northeastern (U.S.) forests. Ecological Modelling 67:3747.

Barnthouse, L. W. 1992. The role of models in ecological risk assessment: a 1990's perspective. Environmental Toxicology and Chemistry 11:1751-1760.

Barrett, G. W. 1968. The effects of an acute insecticide stress on a semi-enclosed grassland ecosystem. Ecology 49: 1019-1035.

Barrett, G. W., and P. J. Bohlen. 1991. Landscape ecology. Pages 149-161 in W. E. Hudson, editor. Landscape linkages and biodiversity. Island Press, Washington, D.C., USA.

Bennett, A. F. 1990. Habitat corridors: their role in wildlife management and conservation. Department of Conservation and the Environment, Victoria, Australia.

Beyer, W. N., and G. Storm. 1995. Ecotoxicological damage from zinc smelting at Palmerton, Pennsylvania. Pages 596608 in D. J. Hoffman, B. A. Rattner, G. A. Burton, Jr., and J. Cairns, Jr., editors. Handbook of ecotoxicology. Lewis, Boca Raton, Florida, USA.

Bird, P. M., and D. J. Rapport. 1986. Contaminants in the environment. Pages 153-208 in State of the Environment Report for Canada, Minister of the Environment, Ottawa, Canada.

Brusven, M. A., and D. J. Walker. 1995. Integrated ecologiceconomic assessment of agricultural nonpoint source pollution on aquatic resources in an watershed and landscape perspective in Idaho. Bulletin of North American Benthological Society 12:88.

Cairns, J., Jr., P. V. McCormick, and B. R. Niederlehner. 1994. A proposed framework for developing indicators of ecosystem health. Hydrobiologia 263:1-44.

Clifford, P. A., D. E. Barchers, D. G. Ludwig, R. L. Sielken, J. S. Klingensmith, R. V. Graham, and M. I. Banton. 1995. An approach to quantifying spatial components of exposure for ecological risk assessment. Environmental Toxicology and Chemistry 14:895-906.

Costanza, R., G. Norton, and B. Haskell, editors. 1992. Ecosystem health: new goals for environmental management. Island Press, Washington, D.C.

Fahrig, L., and K. Freemark. 1995. Landscape-scale effects of toxic events for ecological risk assessment. Pages 193208 in J. Cairns, Jr., and B. R. Niederlehner, editors. Eco- 
logical toxicity testing: scale, complexity, relevance. Lewis, Boca Raton, Florida, USA.

Forman, R. T. T., and M. Godron. 1986. Landscape ecology. John Wiley and Sons, New York, New York, USA.

Freedman, B., and T. C. Hutchinson. 1980. Long-term effects of smelter pollution at Sudbury, Ontario, on forest community composition. Canadian Journal of Botany 58:21232140.

Geckler, J. R., W. B. Horning, T. M. Neiheisel, Q. H. Pickering, and E. L. Robinson. 1976. Validity of laboratory tests for predicting copper toxicity in streams, EPA-600/376-116. Environmental Protection Agency, National Technical Information Service, Springfield, Virginia, USA.

Gherini, S. A., L. Mok, R. J. M. Hudson, G. F. Davis, C. W. Chen, and R. A. Goldstein. 1985. The ILWAS model: formulation and application. Water, Air, and Soil Pollution 26: 425-459.

Golley, F. B. 1995. Reaching a landmark. Landscape Ecology 10:3-4.

Gorham, E. S., E. Bayley, and D. W. Schindler. 1984. Ecological effects of acid deposition upon peatlands: a neglected field in "acid rain" research. Canadian Journal of Fisheries and Aquatic Sciences 41:1256-1268.

Graham, R. L., C. T. Hunsaker, R. V. O'Neill, and B. L. Jackson. 1991. Ecological risk assessment at the regional scale. Ecological Applications 1:196-206.

Grossmann, W. D. 1994. Socio-economic ecological models: criteria for evaluation of state-of-the-art models shown on four cases. Ecological Modelling 75/76:21-36.

Halliday, S. L., and M. L. Wolfe. 1991. Assessing ground water pollution potential from nitrogen fertilizer using a geographic information system. Water Resources Bulletin 27:237-245.

Harwell, M. A., and C. C. Harwell. 1989. Environmental decision making in the presence of uncertainty. Pages 517540 in S. A. Levin, M. A. Harwell, J. R. Kelly, and K. D. Kimball, editors. Ecotoxicology: problems and approaches. Springer-Verlag, New York, New York, USA.

Holl, K., and J. Cairns, Jr. 1995. Landscape indicators in ecotoxicology. Pages 185-197 in D. J. Hoffman, B. A. Rattner, A. G. Burton, and J. Cairns, Jr., editors. Handbook of ecotoxicology. Lewis, Boca Raton, Florida, USA.

Hunsaker, C. T., and D. E. Carpenter. 1990. Environmental monitoring and assessment program: ecological indicators, EPA 600/3-90-060. National Technical Information Service, Springfield, Virginia, USA.

Hunsaker, C. R., R. L. Graham, G. W. Suter II, R. V. O’Neill, L. W. Barnthouse, and R. H. Gardner. 1990. Assessing ecological risk on a regional scale. Environmental Management 14:325-332.

Jackson, D. R., and A. P. Watson. 1977. Disruption of nutrient pools and transport of heavy metals in a forested watershed near a lead smelter. Journal of Environmental Quality 6:331-338.

Johnston, C. A., N. E. Detenbeck, J. P. Bonde, and G. J. Niemi. 1988. Geographic information systems for cumulative impact assessment. Photographic Engineering and Remote Sensing 54:1609-1615.

Jordan, M. J. 1975. Effects of zinc smelter emissions and fire on a chestnut-oak woodland. Ecology 56:78-91.

Lovett, G. M. 1994. Atmospheric deposition of nutrients and pollutants in North America: an ecological perspective. Ecological Applications 4:629-650.

Miller, P. L. 1973. Oxidant-induced community change in a mixed conifer forest. Air Pollution Damage to Vegetation, Advances in Chemistry Series 122:101-117.

Minns, C. K., J. E. Moore, D. W. Schindler, and M. L. Jones. 1990. Assessing the potential extent of damage to inland lakes in eastern Canada due to acidic deposition. III. predicted impacts on species richness in seven groups of aquatic biota. Canadian Journal of Fisheries and Aquatic Sciences 47:821-830.

O'Neill, R. V., D. L. DeAngelis, J. B. Waide, and T. F. H. Allen. 1986. A hierarchical concept of ecosystems. Princeton University Press, Princeton, New Jersey, USA.

O'Neill, R. V., R. H. Gardner, L. W. Barnthouse, G. W. Suter II, S. G. Hildebrand, and C. W. Gehrs. 1982. Ecosystem risk analysis: a new methodology. Environmental Toxicology and Chemistry 1:167-177.

Peterjohn, W. T., and D. L. Correll. 1984. Nutrient dynamics in an agricultural watershed: observations on the role of a riparian forest. Ecology 65:1466-1475.

Ryder, R. A., and C. J. Edwards. 1985. A conceptual approach for the application of biological indicators of ecosystem quality in the Great Lakes Basin. Report to the Great Lakes Science Advisory Board of the International Joint Commission, Windsor, Ontario, Canada.

Schindler, D. W. 1988. Experimental studies of chemical stressors on whole lake ecosystems. Internationale Vereinigung für Theoretische und Angewandte Limnologie 23: $11-41$.

Suter, G. W. II, editor. 1993. Ecological risk assessment. Lewis, Boca Raton, Florida, USA.

Suter, G. W. II. 1990. End points for regional ecological risk assessment. Environmental Management 14:9-23.

Taylor, G. E., Jr., D. W. Johnson, and C. P. Andersen. 1994. Air pollution and forest ecosystems: a regional to global perspective. Ecological Applications 4:662-689.

Troll, C. 1939. Luftbildplan and ökologische Bodenforschung. Zeitschrift der Gesellschaft für Erdkunde 10:241298.

Turner, M. G., E. P. Odum, R. Costanza, and T. M. Springer. 1988. Market and nonmarket values of the Georgia landscape. Environmental Management 12:209-217.

Van Voris, P., W. D. Millard, J. Thomas, and D. Urban. 1993. TERRA-vision-the integration of scientific analysis into the decision-making process. International Journal of Geographical Information Systems 7:143-164.

Vitousek, P. M. 1994. Beyond global warming: ecology and global change. Ecology 75:1861-1876.

Vollenweider, R. A. 1975. Input-output models with special reference to the phosphorus loading concept in limnology. Schweizerische Zeitschrift für Hydrologie 37:53-84.

Westman, W. E. 1979. Oxidant effects on Californian coastal sage scrub. Science 205:1001-1003.

Westman, W. E., and C. V. Price. 1988. Detecting air pollution stress in southern California vegetation using Landsat Thematic Mapper band data. Photogrammetric Engineering and Remote Sensing 54:1305-1311.

Westman, W. E., and P. J. Temple. 1989. Acid mist and ozone effects on leaf chemistry of two western conifer species. Environmental Pollution 57:9-26.

White, F. C., J. R. Hairston, W. N. Musser, H. F. Perkins, and J. F. Reed. 1981. Relationship between increased crop acreage and nonpoint-source pollution: a Georgia case study. Journal of Soil and Water Conservation 36:172-177.

Woodman, J. N., and E. B. Cowling. 1987. Airborne chemicals and forest health. Environmental Science and Technology 21:120-126.

Woodwell, G. M. 1962. Effects of ionizing radiation on terrestrial ecosystems. Science 138:572-577.

Wright, R. F. 1991. Acidification: whole-catchment manipulations. Pages 167-180 in H. A. Mooney, E. Medina, D. W. Schindler, E. D. Schulze, and B. H. Walker, editors. Ecosystem experiments, SCOPE 45. John Wiley and Sons, New York, New York, USA. 